\title{
UNDERSTANDING AND DEFINING INSTRUCTIONAL LEADERSHIP: SCHOOL PRINCIPALS' PERSPECTIVE
}

\author{
Danijela S. Petrovic, \& Selena Vracar \\ Department of psychology, Faculty of Philosophy, University of Belgrade (Serbia)
}

\begin{abstract}
School principal's activities related to the positive effect on the quality of education are manifested in the domain of teaching and learning, i.e. instructional leadership. In the Republic of Serbia, school principals were unjustifiably unattended for a long period of time, and therefore the goal of this exploratory research was to investigate understanding of instructional leadership concept from school principals' perspective. Research sample consisted of 20 elementary and high schools principals and semi-structured interview was conducted. Inductive thematic analysis was used as a method of qualitative data analysis. The following topics were identified in participants' responds: Specifics, Priority and Variability of the instructional leadership. Theme Specifics implies that instructional leadership is defined through activities that constitute it. The narrow comprehension of Specifics is related with the understanding of instructional leadership as a process of improving quality of education through direct work and influence on teachers, while broad comprehension encompasses providing resources so that teachers work could be improved. Priority implies that instructional leadership is defined in the context of other principals' activities (such as finance and administration). Variability is different from other themes because it takes into consideration the change of instructional leadership practice over time and practice by different leaders. Brought together, the three themes mentioned above give a picture of all relevant aspects of instructional leadership. Direct work with teachers that relates with narrow comprehension of instructional leadership versus broad comprehension, represents the dichotomy of work activities presented in the relevant literature. Moreover, when discussing positioning instructional leadership in relation to other principal activities, it is noted that principals recognize its significance, but exert doubt about its priority. It is reasonable that the solution to this dilemma needs to be taken at the national level, making the necessary specifications in the legislation. Interesting questions that these findings raise are related with presence and universality of the mentioned transformation of instructional leadership in the school practice. Finally, it can be concluded that the defining concept of instructional leadership is wide, but within the frames of existent models. Investigating comprehensions of instructional leadership is important for improving the work of school principals. Thanks to the obtained data, it is possible to plan strategies for principals' training in various instructional leadership practices, as well as initiating changes in the legislative framework that regulates the work of principals.
\end{abstract}

Keywords: School leadership, instructional leadership, qualitative study, conceptions, effective schools.

\section{Introduction}

The interest for principals as important actors in the process of improving student achievement dates back to the 70s of the last century (Scheerens, 2012). At that time, a large base of research aimed at discovering the characteristics of effective schools (see, for example, Hall \& Hord, 1987; Edmonds, 1979; Rutter et al., 1979; Leithwood \& Montgomery, 1982; Weber, 1971; Brookover \& Lezotte, 1979; Purkey \& Smith, 1983). The conclusion of the aforementioned research was that principals, as instructional leaders, were one of the key features of effective schools (Leithwood, Begley, \& Cousins, 1990).

In the literature, various models of understanding the effects of instructional leadership are cited (see, for example, Pitner, 1988; Hallinger \& Heck, 1998). A simple, but deliberate division gives Shepard (1996) on instructional leadership in the narrow and broad sense. Broadly speaking, instructional leadership implies dealing with organizational issues and issues of school culture, while in a narrower sense it is confined to behavior that focuses on teaching practices. The goal of instructional leadership (whether it is understood in a narrower or broader sense) is to improve student achievement.

Of all the models of instructional leadership that have been developed, two models predominate over others. These are models developed by Bossert and associates (Bossert et al., 1982), and Hallinger and Murphy (Hallinger \& Murphy, 1985). Bossert and associates use the term "instructional 
management" that conceptualize as actions and strategies of the principals directed at the school's instructional organization and the development of a learning culture aimed at improving educational outcomes. In his work, Bossert et al. (1982) chose the term instructional management because they concluded that the role of director is reduced to managerial tasks oriented to the coordination and control of curriculum and teaching. Another dominant model that provides a clear definition of instructional leadership is, as mentioned above, presented in the work of Hallinger and Murphy (Hallinger \& Murphy, 1985). The conceptual framework of this model consists of three dimensions: defining a school mission, managing the curriculum and developing a learning culture. Each of the three dimensions is further described by the functions of instructional leadership.

In the Republic of Serbia school principals are in a very challenging position in view of the disproportion of set requirements (regulated by legal acts), and the support provided to them (in the form of training programs or seminars intended for professional development). Data from the TALIS 2013 survey (OECD, 2014) indicate, on one hand, the high representation of instructional leadership practice in schools in Serbia: the cumulative frequency (for answers to all three items related to instructional leadership $^{1}$ ) for Serbia is 249.3 , while TALIS average is 208.2. Therefore, the percentage of principals who say that "often" or "very often" engage in these activities is over $80 \%$. On the other hand, the data indicates that the principals are undertrained (in the sense of not attending relevant training) either during initial education, or during later professional development. In Serbia, training from instructional leadership has never been attended by as many as $53.4 \%$ of principals (TALIS average is $22.2 \%$ ). There are several actors, from whom they can seek support, starting from the resources in the school itself, through the Society of School Principals of Serbia, to institutions and organizations of a national and international character. Common to all mentioned, potential, sources of assistance is that their inclusion depends, and it is left to the initiative of the director himself. Taking into account the importance they have when it comes to ensuring the quality of the work of the institution, it is clear that their professional development should not be left to their initiative, and that they must be systematically addressed, in the same way as the Law on the Foundations of the Education prescribes (Official Gazette RS, No. 72/2009). Considering the importance of instructional leadership, and in contrast, a modest database on the same in a domestic context, the goal of this exploratory research is to investigate the understanding of instructional leadership from the perspective of the school principals themselves.

\section{Methodology}

\subsection{Qualitative paradigm}

A qualitative paradigm is set up as an adequate research response to the study of instructional leadership for several reasons. Firstly, the instructional leadership in Serbia was not at all the subject of researchers' interest, and it is therefore impossible to formulate clear and precise hypotheses for quantitative research. Secondly, it is suitable for the purpose of deeper understanding and clarification of data related to the instructional leadership gathered in the TALIS 2013 survey (OECD, 2014). The designed study thus provides an opportunity for research participants to share with the researcher their personal experience of the investigated phenomenon.

Qualitative research is a constant reminder that the views and activities of other people are an inexhaustible source of knowledge and can never be fully covered. In this respect, the data collected by the qualitative study not only represent a complement to quantitative indicators but potentially can produce some relevant findings that could be obtained exclusively through this method, thanks to a particular type of sensitivity of qualitative studies (Viling, 2016).

\subsection{Sample}

Four principals were selected by the recommendation of the expert in educational leadership, while the rest of the sample was collected by the snowball method - based on the recommendations given by the initial sample of four principals. Besides to the recommendations of expert and colleagues, two additional indicators for the selection of principals to enter the sample were: (1) training in the field of instructional leadership, and (2) evaluation scores from the external evaluation of schools (for two domains: the School Ethos and the School Management and Leadership). The reason for choosing the School Ethos as an additional criterion is based on data from TALIS 2013 for Serbia - namely, the connection between practicing instructive leadership and indicators: the school climate - respect for each other is 0.26 (OECD, 2014). In total 20 school principals participated in the research (see Table 1).

\footnotetext{
${ }^{1}$ Principals were asked to indicate how frequently they engaged in the following activities in their school during the preceding 12 months: I took actions to support co-operation among teachers to develop new teaching practices; I took actions to ensure that teachers take responsibility for improving their teaching skills; I took actions to ensure that teachers feel responsible for their students' learning outcomes (OECD, 2014).
} 
Table 1. Characteristics of the sample.

\begin{tabular}{|c|c|c|c|c|c|}
\hline \multicolumn{2}{|c|}{ Gender distribution } & \multicolumn{2}{|c|}{ Type of the school } & \multicolumn{2}{c|}{ City } \\
\hline Male & Female & Elementary school & Secondary school & Belgrade & Other \\
\hline $45 \%$ & $55 \%$ & $55 \%$ & $45 \%$ & $80 \%$ & $20 \%$ \\
\hline
\end{tabular}

The principals of the sample have on average 17.3 years of teaching experience (which is 3.4 years more than the average for the Republic of Serbia in the TALIS 2013 study (OECD, 2014)). Most principals previously worked as subject teachers (i.e. they were teachers from 5th to 8th grade in elementary school, or in secondary school), two principals had previously been in the position of a professional associate - pedagogue, and one director previously worked as a class teacher (i.e. teaching from 1th to 4th grade in elementary school). On average, principals have 9.2 years of experience in a given position (which is 1.8 years more than the average for the Republic of Serbia in the TALIS 2013 study (OECD, 2014)). When it comes to external evaluation data for the assessment of the ethos and organization of school work and management, only good and fully-matched standards were represented in the sample, with the majority of the sample (70\%) being schools where these areas were rated at the highest level, the level 4. For the three schools from the sample $(15 \%)$, there are no data on the listed areas, because the external evaluations were not yet conducted in the given schools. Participation in training from instructional leadership is characterized for respondents who are on the master program "Leadership in Education" (25\% of the sample).

\subsection{Data collection and analysis}

A semi-structured interview was selected as a data collection technique. Some examples of questions from the interview guide are: "How do you understand the concept of instructional leadership?", "How do you see its significance?", with questions to encourage conversations such as: "Why do you think that?", "Can you explain a bit what did you say?", etc. Principals were invited to express their personal opinion, to speak from their own perspective. In the transcription of the interview, a denaturalized approach was used (Elo \& Kyngäs, 2008), which represents a complete and faithful form of transcription, but without the requirement to indicate idiosyncratic speech elements.

Inductive thematic analysis was used as a method of qualitative data analysis in this study. In general, the thematic analysis represents a method for identifying and organizing patterns in the content and meaning of qualitative data (Viling, 2016). An inductive approach functions from the bottom up - researchers access the data without a theoretically framed encoding frame, the topics are based on data (Boyatzis, 1998 according to Wing, 2016).

\section{Results} in Table 2.

In the director's narratives, three themes have been identified. The tabular display of data is given

Table 2. How school principals define instructional leadership.

\begin{tabular}{|c|l|c|c|}
\hline & \multicolumn{3}{|c|}{ Instructional leadership } \\
\hline Themes & \multicolumn{1}{|c|}{ Specifics } & Priority & Variability \\
\hline Categories & The narrow & Extremely important & \\
& comprehension & Relatively important & \\
& The broad comprehension & & \\
\hline
\end{tabular}

A. Specifics. Theme Specifics implies that instructional leadership is defined through activities that constitute it. Within the theme "Specifics" the following categories have been identified:

A1. The narrow comprehension. This category includes the answers of principals who see instructional leadership as a process of improving the quality of education through direct work with teachers. The principal follows the work of teachers, gives suggestions for their improvement, takes care of maintaining teacher motivation, and is present during the whole process of adaptation to working conditions. The principal who does so has the characteristics of an instructional leader. Also, this category includes a response group that emphasizes the word "leader". Namely, the principal is seen as someone who leads the introduction of innovations in educational practice or encourages teachers to do this, if he/she is "not innovative" in this regard. The reason why these responses also fall into this category is reflected in the fact that there is still direct influence and work between principals and teachers, with the specification of the operation present here. 
Example: The school principal as an instructional leader must seriously address the teacher motivation (female, elementary school).

A2. The broad comprehension. Principals whose answers fall into this category do not limit instructional leadership solely to the process of direct influence on teachers. Namely, they treat as an equally important aspect of instructional leadership the procurement of equipment and resources so that teachers can work efficiently. In other cases, the only possible direction of the activity of instructional leadership is seen in the case of procurement of the mentioned funds. Thus, this category includes answers through which instructional leadership is seen as a type of leadership which primarily has indirect consequences for improving the quality of teaching. Principals represent a secondary link in this process, in the sense that they operate through the creation of adequate working conditions or the formation of teams that will directly work with teachers.

Example: Instructional leadership implies the creation of an incentive environment in school, both in terms of material resources, the acquisition of other resources ... (female, elementary school).

$B$. Priority. The concept is defined by the significance it has, in terms of how it is positioned in the context of all the work that the director is doing. Within the theme "Priority" the following categories have been identified:

B1. Extremely important. For principals whose answers fall into this category, instructional leadership is the most important aspect of the principals' work. The education and quality of education acquired in school is seen as the primary function of a school, and principals perceive their role as bearers in achieving the set goal of quality education. Furthermore, it is important to note that some principals fail to put instructional leadership as a priority of their work, but regardless of the fact that they do not come to deal with it, they see it as extremely important as something that should give priority to their work.

Example: The basic mission of each school is quality teaching (male, secondary school).

B2. Relatively important. Everything is important and everyone is important. Instructional leadership is one aspect of the work of the principal whose importance is not denied, but also does not stand out in relation to others. Administrative tasks, dealing with finances and the like are also the responsibilities of principal which must not be ignored. Therefore, the principal should take actions so that everything functions well, perform all the tasks prescribed to him/her, and no job has, nor should have, a priority over another.

Example: The principal must be a lawyer, an electrician and a plumber and he must supervise everything that happens in school... (female, primary school).

C. Variability. This category of responses differs in relation to others by adding the time component to the concept of instructional leadership. Namely, principals with longer working years, find their role changed. The beginning is seen as a period of intensive work and "putting things in order", while work in the later years refers to the maintenance of a defined structure and established processes. In addition, the variability of performing the role itself can be seen in the way that principals use different approaches for organizing it.

Example: Like every beginner, you have the need to organize everything, to be in control of everything. It is much easier now, now I only coordinate the work of the teams... (female, elementary school).

\section{Discussion and conclusion}

As an expression of the efforts of the principal to determine the instructional leadership, three tendencies were identified: defining over the tasks from which it consists, defining in the context of other tasks and finally, defining the changes in the operation of which it consists. When it comes to defining instructional leadership through the jobs it consists of, it can be recognized dichotomy given by Sheppard (1996) to the instructional leadership in narrow and instructional leadership in the broad sense. So, we can notice that principals have different conceptions about the breadth of their field of activity as instructional leaders. Considering that the same disagreement exists in scientific circles, the registered situation isn't a surprise. Furthermore, when it comes to the second tendency of determining through positioning in relation to other jobs, we testify to the situation of recognized importance, but also the uncertainty about allocating it in relation to other tasks. It seems that the principals are guided by the responsibilities as defined by the legislation and that they want to stay within the given framework and perform all their duties equally, without any special allocation that the law does not do. Therefore, it is very clear that the educational law influences the formation of practice (Official Gazette RS, No. 72/2009). The law does not give priority to one area of work in relation to the other, and neither principal in his/her practices do so. Finally, it is interesting to note the presence of observations concerning the transformation of instructional 
leadership during the course of time. The transformation itself is moving from direct engagement and high presence to more mediocre and delegated tasks. Mentioned observations provoke interesting questions about presence and universality of this transformation of instructional leadership in practice.

On the basis of data acquired, the following recommendations have been formulated:

- Revisions to the legislation regarding the allocation of instructional leadership as a priority of the principal work;

- Expert support should be designed to follow the jobs that fall into the narrow and broad understanding of instructional leadership;

- Organize seminars that will be directed toward developing the strategies for determining work priorities;

- To establish a network of principals from different schools in order to provide mutual support and horizontal learning.

\section{Acknowledgements}

This work was supported by the Ministry of Education, Science and Technological Development, Republic of Serbia (project number 179018).

\section{References}

Bossert, S., Dwyer, D., Rowan, B., \& Lee, G. (1982). The instructional management role of the principal. Educational Administration Quarterly, 18(3), 34-64. doi: 10.1177/0013161x82018003004.

Brookover, W. B., \& Lezotte, L. W. (1979). Changes in school characteristics coincident with changes in student achievement. East Lansing, MI: Institute for Research on Teaching, Michigan State University.

Edmonds, R. (1979). Effective schools for the urban poor. Educational Leadership, 37(1), 15-24. Elo, S., \& Kyngäs, H. (2008). The qualitative content analysis process. Journal of Advanced Nursing, 62(1), 107-115. doi: 10.1111/j.1365-2648.2007.04569.x.

Elo, S. \& Kyngäs, H. (2008). The qualitative content analysis process. Journal of Advanced Nursing, Vol. 62, No. 1, 107-115.

Hall, G. E., \& Hord, S. M. (1987). Change in schools: facilitating the process. Albany: State University of New York Press.

Hallinger, P., \& Heck, R. H. (1998). Exploring the principal's contribution to school effectiveness: 1980-1995. School Effectiveness and School Improvement, 9(2), 157-191. doi: 10.1080/0924345980090203.

Hallinger, P., \& Murphy, J. (1985). Assessing the instructional management behavior of principals. Elementary School Journal, 86(2), 217-248. doi: 10.1086/461445.

Leithwood, K. A., Begley, P. T., \& Cousins, J. B. (1990). The Nature, Causes and Consequences of Principals' Practices: An Agenda for Future Research.Journal of Educational Administration, 28(4). doi:10.1108/09578239010001014.

Leithwood, K., \& Montgomery, D. (1982). The role of the elementary principal in program improvement. Review of Educational Research, 52(3), 309-339. doi: 10.3102/00346543052003309.

OECD (2014). TALIS 2013 Results: An International Perspective on Teaching and Learning. Paris: OECD.

Law on the Foundations of the Education System', Official Gazette RS, No. 72/2009, 52/2011 and $55 / 2013$

Pitner, N. (1988). The study of administrator effects and effectiveness. In N. Boyan (Ed.), Handbook of research in educational administration (106-132). New York: Longman.

Purkey, S., \& Smith, M. (1983). Effective schools: A review. The Elementary School Journal, 83 (4), 427-452. doi: 10.1086/461325.

Rutter, M., Maughan, B., Mortimore, P., Ouston, J., \& Smith, A. (1979). Fifteen Thousand Hours: Secondary schools and their effects on children. Cambridge: Harvard University Press.

Scheerens, J. (2012). School leadership effects revisited review and meta-analysis of empirical studies. Dordrecht: Springer.

Sheppard, B. (1996). Exploring the transformational nature of instructional leadership. The Alberta Journal of Educational Research, 42(4), 325-344.

Viling, K. (2016). Kvalitativna istraživanja u psihologiji. Beograd: CLIO.

Weber, G. (1971). Inner-city children can be taught to read: four successful schools. Washington: Council for Basic Education. 